\title{
Antibacterial, antioxidant properties of Solanum trilobatum and sodium hydroxide-mediated magnesium oxide nanoparticles: a green chemistry approach
}

\author{
S NARENDHRAN*®D, M MANIKANDAN and P BABY SHAKILA \\ Department of Bioscience, Sri Krishna Arts and Science College, Sugunapuram, Kuniamuthur P.O., Coimbatore 641008, \\ India \\ *Author for correspondence (narendhransumathi@gmail.com)
}

MS received 18 May 2018; accepted 28 January 2019; published online 25 April 2019

\begin{abstract}
A comparative study of Solanum trilobatum-mediated magnesium oxide (St-MgO) nanoparticles (NPs) and sodium hydroxide-mediated $\mathrm{MgO}(\mathrm{Che}-\mathrm{MgO}) \mathrm{NPs}$ are synthesized using magnesium nitrate precursor. The characterization analyses, such as ultraviolet-visible spectroscopy (UV-Vis), Fourier transform infrared spectroscopy (FTIR), X-ray diffraction (XRD), energy-dispersive X-ray diffraction (EDX), scanning electron microscopy (SEM) and particle-size analysis were carried out. To determine the antioxidant activity of MgO NPs by 2,2-diphenyl-1-picrylhydrazyl (DPPH) method and antibacterial activity against Escherichia coli (MTCC: 912), Bacillus subtilis (MTCC: 121) and Streptococcus pyogenes (MTCC: 1925), was performed by the well-diffusion method. The UV-Vis analysis of St-MgO, Che-MgO confirmed the formation of MgO NPs that have a broad absorption peak at 362 and $374 \mathrm{~nm}$, respectively. IR spectrum of synthesized St-MgO and Che-MgO exhibits a high-intensity band at 440 and $460 \mathrm{~cm}^{-1}$, respectively. XRD analysis indicates that synthesized St-MgO, Che-MgO were crystal in nature and EDX confirmed the composition of MgO-NPs. SEM analysis revealed that $\mathrm{St}-\mathrm{MgO}$ and $\mathrm{Che}-\mathrm{MgO}$ NPs were spherical in shape without aggregation. Particle-size analysis confirmed that the average particle sizes of St-MgO and Che-MgO NPs were 30 and $42 \mathrm{~nm}$, respectively. DPPH assay of St-MgO NPs has higher absorbance value, which indicates the high antioxidant capacity compared with ascorbic acid. St-MgO NPs are effective against bacterial pathogens, such as E. coli $(16.66 \pm 0.66)$, B. subtilis $(16.00 \pm 0.88)$ and S. pyogenes $(13.66 \pm$ $2.08)$ at $100 \mathrm{mg} \mathrm{ml}^{-1}$ concentration when compared with Che- $\mathrm{MgO}$ and the control $(P<0.001)$. Thus, the result suggested that safer use of biologically synthesized MgO NPs can act as effective antioxidant and antibacterial agents in the field of biomedicine.
\end{abstract}

Keywords. Antibacterial activity; antioxidant activity; magnesium oxide nanoparticles; Solanum trilobatum.

\section{Introduction}

Nowadays, researchers have developed exciting new materials that are nanosized to progress towards unique and tunable properties of the applied materials. An important aspect of nanoscience is related to design experimental methods for the synthesis of nanoparticles (NPs) with different chemical compositions, sizes, shapes and properties. Recently, researchers have tried to find biological methods for the synthesis of NPs that will act as alternatives to chemical or physical methods. Biological methods for the production of NPs are considered safe and environmentally friendly; they are also cost-effective and ensure the complete elimination of toxic chemicals. In addition, the synthesis of NPs using biological means, especially plants, is biocompatible, as they secrete functional biomolecules which actively reduce metal ions.

Magnesium oxide ( $\mathrm{MgO})$ NPs are important materials used in catalysts, photonic and electronic devices. $\mathrm{MgO}$ particles are inorganic compounds with wide band gaps. It has low heat capacity, high melting point and highly functional. Therefore, it is used for insulation application in various areas [1,2]. $\mathrm{MgO}$ NPs act as bactericidal agents because the surface of the particle is synthesized with superoxide anion. Al-Hazmi et al [3] recognized that $\mathrm{MgO}$ NPs have antibacterial activity due to their size, shape and surface properties. Due to their smaller size, nanomaterials have novel properties, which is different from others [4,5]. Bhatte et al [5] demonstrated that the antimicrobial activity of $\mathrm{MgO}$ NPs of size from 4 to $10 \mathrm{~nm}$ is efficient as bactericidal agents. Doss et al [6] explained that particle size $<40 \mathrm{~nm}$ has increased antibacterial efficacy.

$\mathrm{MgO}$ NPs are synthesized by various methods that include vapour liquid solid, electrochemical process, colloidal micelles, micro oven and ultrasonic. Recently, most researchers follow biological synthesis of NPs rather than physical and chemical methods. They consider that the biological synthesis of NPs are eco-friendly, cost-effective and with low toxicity [7]. In biological synthesis, functional biomolecules of plant metabolism reduce the metal ion [8]. In recent 
reports, biological synthesis of MgO NPs from neem, Clitoria ternatea, Parthenium and Brassica oleracea have been carried out successfully [9-11]. Despite the availability of much less information about green route synthesis of $\mathrm{MgO}$ NPs, it is still an unknown area and requires further exploration. In the previous investigation, Krishnamoorthy et al [11] demonstrated that the green route synthesis of $\mathrm{MgO}$ NPs has antibacterial activity against foodborne pathogens.

$\mathrm{MgO}$ NPs are safe materials to humans. Inorganic antimicrobial agents $(\mathrm{MgO}, \mathrm{ZnO}$, etc.) have a high inhibition rate against various Gram-positive and Gram-negative bacteria, which is a safe and stable material when compared to organic antimicrobial agents. In the medical field, $\mathrm{MgO}$ material showed promising application for bone regeneration, sore stomach, relief of heartburn and tumour treatment [12-14]. Solanum trilobatum $\mathrm{L}$. belongs to the family Solanaceae. This medicinal plant is used to treat asthma, tuberculosis, respiratory and liver diseases, because it contains a rich amount of nutrients [15]. Phytochemicals like sobatum, solaine, solasodine and glycoalkaloid are the major constituents responsible for antimicrobial and anticancer activities [16]. This plant contains a high percentage of alkaloids and carbohydrates that stimulates a strong immune effect. Due to these overall properties of $S$. trilobatum, it is a good candidate for the synthesis of NPs [17]. In biological synthesis, S. trilobatum extract is used to synthesize titanium, silver [18] and palladium NPs [19].

MgO NPs are highly ionic nanoparticulate metal oxides with extremely high surface areas and unusual crystal morphologies. Nanoscale $\mathrm{MgO}$ possesses unique optical, electronic, magnetic, thermal, mechanical and chemical properties due to its characteristic structures. $\mathrm{MgO}$ is an important functional metal oxide that has been widely used in various fields, such as catalysis, refractory materials, paints and superconductors. Review of literature reveals that there are several methods for the synthesis of nano-sized $\mathrm{MgO}$ particles, including the sol-gel method, chemical gas-phase deposition, laser vapourization, hydrothermal synthesis and combustion aerosol synthesis. Biological methods for the synthesis of MgO NPs with the use of plant materials have not been widely exploited.

In this present study, we investigate green route synthesis of $\mathrm{MgO}$ NPs using $S$. trilobatum (St-MgO) aqueous extract and chemical synthesis (Che-MgO) of $\mathrm{MgO}$ NPs by co-precipitation method. The crystalline and morphology characters of $\mathrm{St}-\mathrm{MgO}$ and $\mathrm{Che}-\mathrm{MgO}$ were analysed using ultraviolet-visible spectroscopy (UV-Vis), Fourier transform infrared spectroscopy (FTIR), X-ray diffraction (XRD), energy-dispersive diffraction X-ray (EDX), scanning electron microscopy (SEM) and particle-size analysis. To determine antibacterial activity of green and chemical $\mathrm{MgO}$ NPs, the well-diffusion method was performed against test organisms like Escherichia coli (MTCC: 912), Bacillus subtilis (MTCC: 121) and Streptococcus pyogenes (MTCC: 1925).

\section{Materials}

S. trilobatum plants were collected from Avarampalayam region, Coimbatore, Tamil Nadu, India. Chemicals used in this experiment were of analytical grade, purchased from Sigma Aldrich. Bacterial pathogens (E. coli MTCC 912, B. subtilis MTCC 121 and S. pyogenes MTCC 1925) were obtained from IMTech, Chandigarh, India. The bacterial pathogens are subcultured and maintained in nutrient agar media for future use.

\section{Methodology}

\subsection{Synthesis of St-MgO and Che-MgO}

S. trilobatum leaf was washed with distilled water; shade dried for 5 days; powdered using mortar and pestle. A weight of

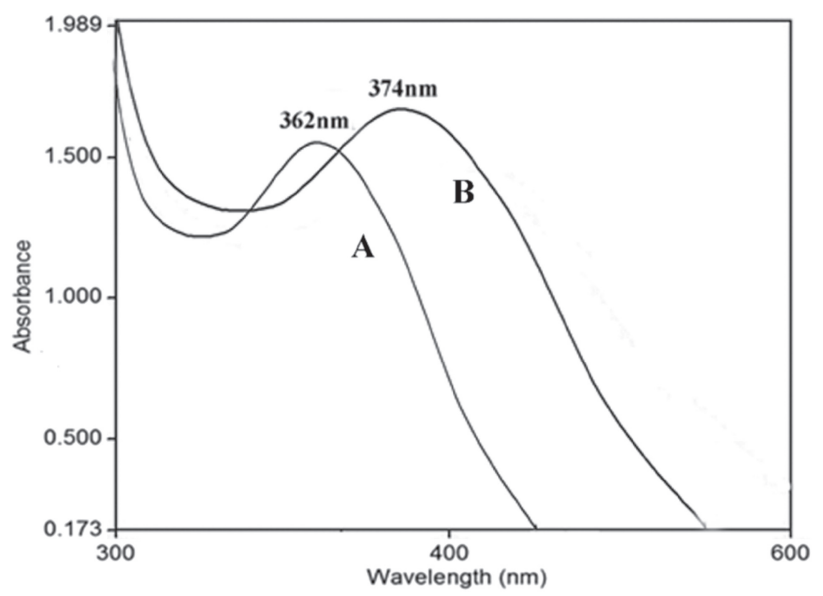

Figure 1. UV-Vis analysis of (A) S. trilobatum-mediated $\mathrm{MgO}$ NPs observed at $362 \mathrm{~nm}$ and (B) magnesium nitrate-mediated $\mathrm{MgO}$ NPs observed at $374 \mathrm{~nm}$.

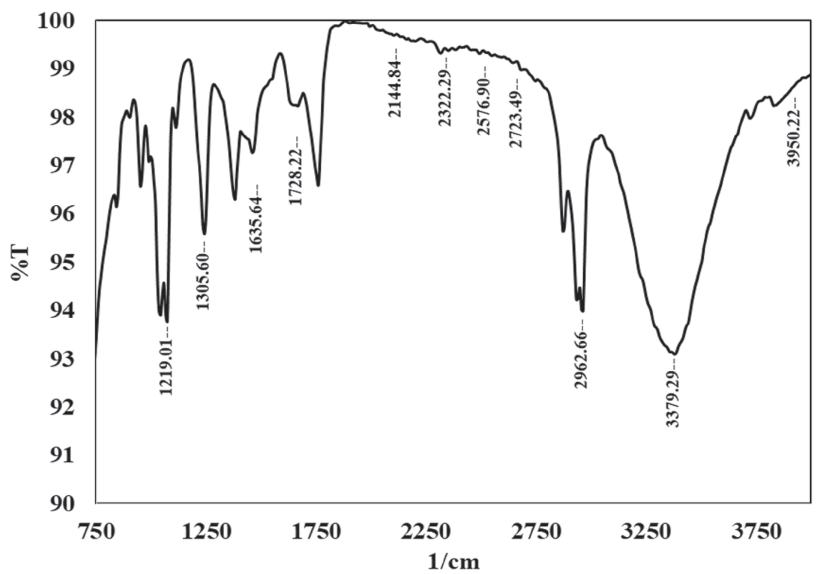

Figure 2. FTIR analysis of S. trilobatum leaf aqueous extract shows the presence of aliphatic amine, alkanes, unsaturated ester, alkynes, carboxylic acid, amines, alcohol and phenol functional group. 
$1 \mathrm{~g}$ of powdered leaf sample was dissolved in $100 \mathrm{ml}$ of distilled water and heated at $100^{\circ} \mathrm{C}$ for $5 \mathrm{~min}$. After heating, the sample was filtered with Whatman filter paper and the crude extract was stored for further use. A $50 \mathrm{ml}$ of crude plant extract was added (dropwise) to a beaker, which contained $50 \mathrm{ml}$ magnesium nitrate $(0.5 \mathrm{M})$ solution under magnetic stirring for $4 \mathrm{~h}$ until the formation of precipitate settled in the bottom of the conical flask. This precipitate was centrifuged at $5000 \mathrm{rpm}$ for $5 \mathrm{~min}$ and the pellets were collected. This precipitate was further purified by washing with Millipore water and ethanol for several times to remove impurities. After the purification step, the precipitate was annealed at $400^{\circ} \mathrm{C}$ for $8 \mathrm{~h}$ and was finely powdered by using mortar and pestle. The final product was stored in a screw-capped bottle for further use.

To synthesize Che-MgO NPs, a $0.5 \mathrm{M}$ magnesium nitrate $\left(\mathrm{MgNO}_{3}\right)$ and $0.1 \mathrm{M}$ sodium hydroxide $(\mathrm{NaOH})$ were prepared in double-distilled water. A $100 \mathrm{ml}$ of $\mathrm{MgNO}_{3}$ solution was added dropwise to a beaker that contained $100 \mathrm{ml}$ of
$\mathrm{NaOH}$ solution placed in a magnetic stirrer with high-speed stirring. After $20 \mathrm{~min}$ of stirring, the beaker was kept for $2 \mathrm{~h}$ undisturbed for the settlement of the precipitate. The precipitated Che-MgO NPs washed with Millipore water was followed by ethanol washing until the removal of impurities and then vacuum dried at $80^{\circ} \mathrm{C}$ in a hot air oven. Then Che$\mathrm{MgO}$ NPs were transferred to airtight screw-capped bottle for further analysis [9].

\subsection{Characterization of St $-\mathrm{MgO}$ and Che- $\mathrm{MgO}$}

The optical density and band gap energy were determined by UV-Vis spectroscopy (UV-2450, Shimadzu). The crystalline structure of magnesium NPs was observed by XRD with $\mathrm{CuK} \alpha$ radiation (Perkin-Elmer spectrum). FTIR (PerkinElmer 1725X) was used to study the functional group, which is responsible for the reduction of magnesium NPs from plant sample assay. Element composition and morphology of $S$. trilobatum and sodium hydroxide-mediated magnesium NPs
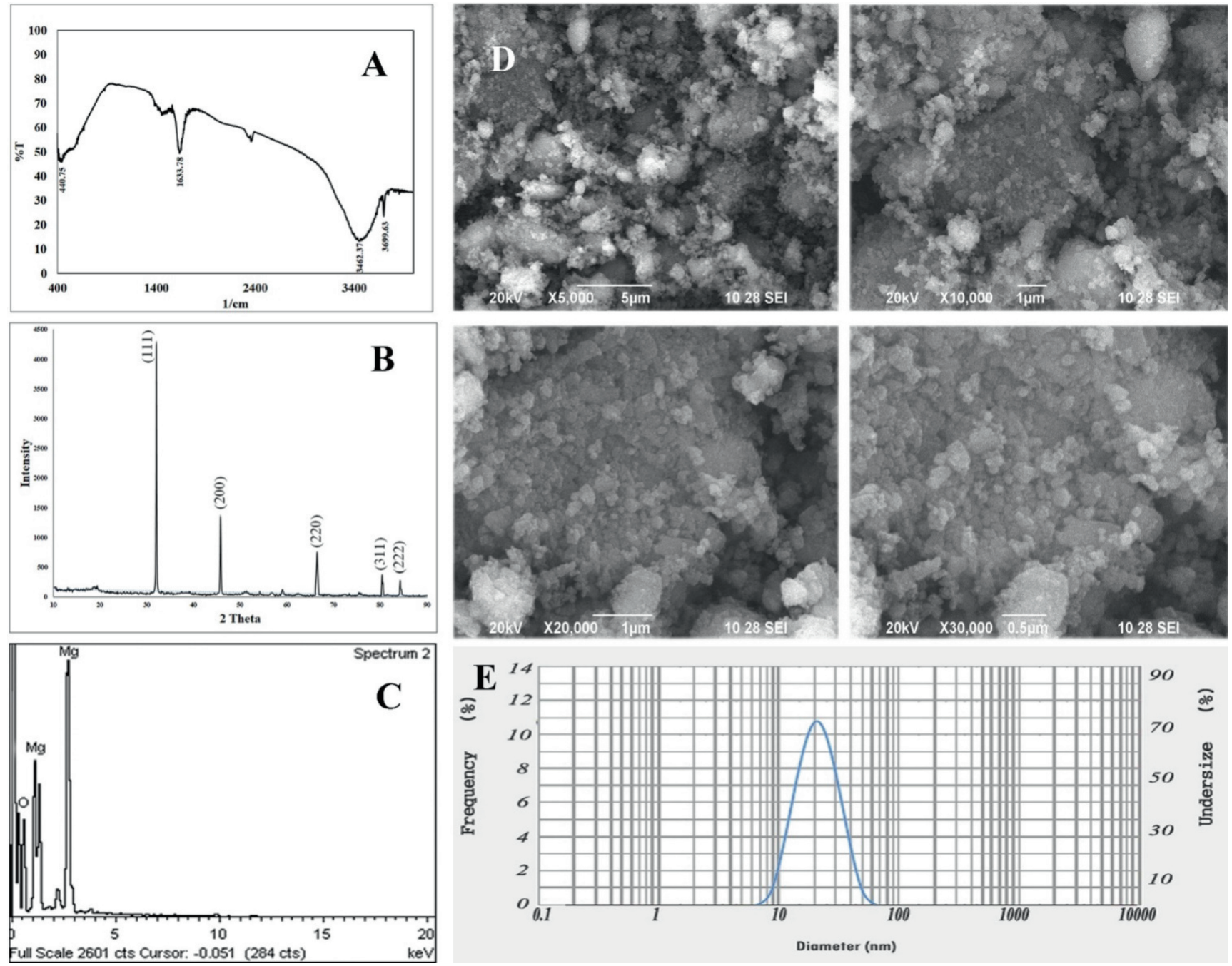

Figure 3. Characterization of St-MgO: (A) FTIR spectroscopy analysis, (B) XRD, (C) EDX, (D) SEM images of synthesized St-MgO at different resolutions and (E) particle-size analysis. 
were analysed using EDX (Model QuanTax 200, Germany) and SEM (Model JSM 6390LV), to determine the size of MgO NPs by particle-size analysis [20].

\subsection{Antioxidant and antibacterial activities of magnesium NPS}

Antioxidant activity of MgO NPs by DPPH radical scavenging activity was analysed according to the method described by Rai and Ingle et al [21], in which DPPH (0.1 mM) reagent taken as a control and the ascorbic acid was used as a standard (lower the absorbance, higher the free radical scavenging activity). Then, the absorbance of the reaction mixture was read at $517 \mathrm{~nm}$ with a Shimadzu UV2450 spectrophotometer. The free radical scavenging activity of the samples was calculated by the formula:

$$
\begin{gathered}
\% \text { Scavenging activity }=\text { Control OD } \\
- \text { Test OD/Control OD } \times 100 .
\end{gathered}
$$

Antibacterial activities of $S$. trilobatum and sodium hydroxide-mediated magnesium NPs were determined by the well-diffusion method. Bacterial culture swapped on nutrient agar plate and $5 \mathrm{~mm}$ size of well-punched on agar surface with the help of sterile gel puncher. Various concentrations of magnesium NPs such as 25, 50, 75, $100 \mathrm{mg} \mathrm{l}^{-1}$ and streptomycin (positive control, $10 \mu \mathrm{g} \mathrm{ml}^{-1}$ ) were added in appropriate wells. The plates were incubated at room temperature for $24 \mathrm{~h}$. The zone of inhibition was measured (millimetre in diameter) and mean values were recorded [26,27].

\subsection{Statistical analysis}

All results are presented as mean \pm standard deviation (SD). Using SPSS statistical tool, all data were analysed at the significant level $\leq 0.05$ by $t$-test to test the difference between $\mathrm{St}-\mathrm{MgO}$, Che-MgO and the control group. One-way analysis of variance (ANOVA) was also performed to test the effect of $\mathrm{MgO}$ NPs dose on the test parameters. $P$ values of $\leq 0.05$ were considered statistically significant.
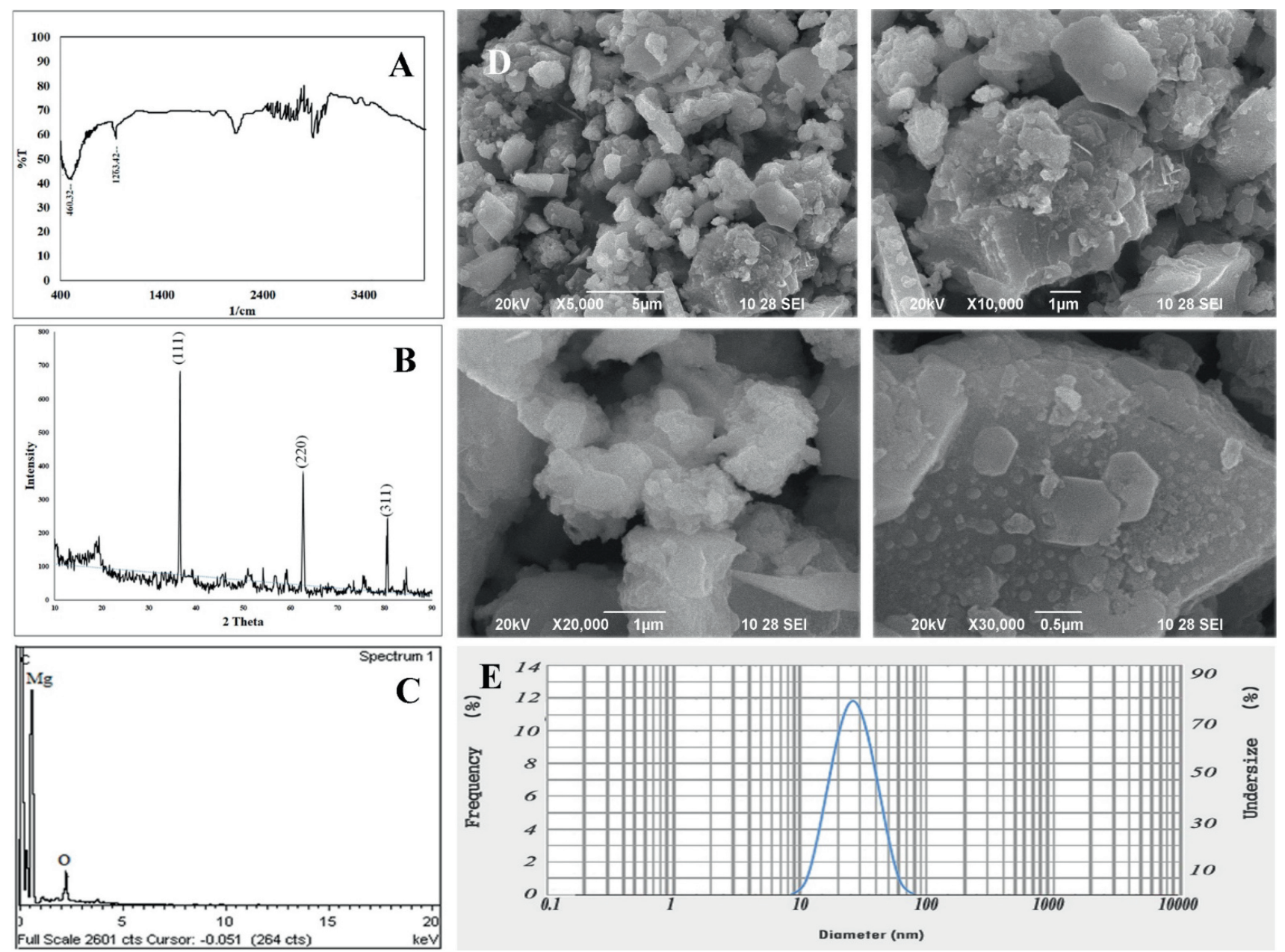

Figure 4. Characterization of Che-MgO: (A) FTIR spectroscopy analysis, (B) XRD, (C) EDX (D) SEM and (E) particle-size analysis. 


\section{Results and discussion}

\subsection{UV-Vis, FTIR and XRD analyses}

The UV-Vis absorption spectra of St-MgO and Che-MgO are shown in figure 1. UV-Vis absorption spectroscopy is the most widely used method for characterizing the optical properties and electronic structure of NPs, as the absorption bands are related to the diameter and aspect ratio of metal NPs. The absorption spectrum of synthesized St-MgO recorded the peak at $362 \mathrm{~nm}$ and colour change observed from brown to pale yellow. For chemical synthesis (Che- $\mathrm{MgO})$, the peak was observed at $374 \mathrm{~nm}$. Palanisamy and Pazhanivel [19] synthesized $\mathrm{MgO}$ NPs using betel leaf extract and observed a wide range of optical density at $320 \mathrm{~nm}$. They concluded that synthesis of MgO NPs and band gap of biological synthesis are low when compared to chemical synthesis. Rajeshwari et al [22] and Rajiv et al [23] described that absorption peak range of 300-400 nm indicates the presence of metal oxide NPs. According to Al-Hazmi et al [3], light wavelengths in the range of 300-800 $\mathrm{nm}$ are used for characterizing various metal NPs in the size range between 2 and $100 \mathrm{~nm}$. More specifically, the antioxidant properties are related to the number of hydroxyl groups in the particle as well as the level of their esterification. Increase in methyl and hydroxyl group may enhance the antioxidant activity of NPs.

FTIR was used to identify the possible biomolecules which are responsible for the reduction and capping of MgO NPs. FTIR analysis of $S$. trilobatum leaf extract show peaks at $1219.01,1365.60,1635.64,1728.22,2144.84,2322.29$, 2576.90, 2723.49, 2962.66, 3379.29 and $3950.22 \mathrm{~cm}^{-1}$ (figure 2). It corresponds to aliphatic amine (C-N stretch), alkanes ( $\mathrm{C}-\mathrm{H}$ rock), unsaturated ester $(\mathrm{C}=\mathrm{O}$ stretch), alkynes $(-\mathrm{C}=\mathrm{C}-$ stretch, $\mathrm{C}-\mathrm{H}$ stretch$)$, carboxylic acid $(\mathrm{O}-\mathrm{H}$ stretch), amines ( $\mathrm{N}-\mathrm{H}$ bend), alcohol and phenol (O-H stretch). This functional group acts as reducing and capping agent for the synthesis of MgO NPs.

FTIR analysis determines the functional group which is attached to the surface of St-MgO (figure 3A). The peaks at $440.75,1633.78,3462.37$ and $3699.63 \mathrm{~cm}^{-1}$ refer to $\mathrm{N}-\mathrm{H}$ bend and $\mathrm{O}-\mathrm{H}$ stretch. These peaks are responsible for alkyl halide, primary amine, alcohol and phenol group. The strong peaks at 440 and $3699 \mathrm{~cm}^{-1}$ was assigned to $\mathrm{Mg}-\mathrm{O}$ stretching vibration. The remaining peaks (1633 and $3462 \mathrm{~cm}^{-1}$ ) in FTIR spectrum represent stability and capping of $\mathrm{MgO}$ NPs. IR spectra of Che-MgO NPs exhibit a high-intensity band around 460.32 and $1263.42 \mathrm{~cm}^{-1}$ (figure 4A).

Ganapathi et al [7] explained the functional group of magnesium NPs using Olea europaea extract in a single step. They concluded that FTIR spectrum peaks at 451 and 3699 $\mathrm{cm}^{-1}$ was assigned to $\mathrm{MgO}$ NPs. Earlier, Al Hazmi et al [3] explained the FTIR spectra of MgO NPs synthesized using Artemisia abrotanum herb extract. The spectra showed bands at 3308, 2139, 1635, 1346, 419 and $407 \mathrm{~cm}^{-1}$. The strong infrared band near $3308 \mathrm{~cm}^{-1}$ was observed for the presence of $\mathrm{O}-\mathrm{H}$ bond vibrations of the hydroxyl group. The most intense band at $1635 \mathrm{~cm}^{-1}$ represents vibrations of $\mathrm{C}=\mathrm{O}$, typical for the structure of flavonoids, which can be found in A. abrotanum herb extract. The peak which appeared at $2139 \mathrm{~cm}^{-1}$ may indicate the presence of alkynes group. The absorption band at $1346 \mathrm{~cm}^{-1}$ is related to $\mathrm{C}-\mathrm{H}$ bonding vibrations of the aromatic tertiary amine group. The peaks observed at 419 and $407 \mathrm{~cm}^{-1}$ indicate the presence of $\mathrm{MgO}$ NPs. These results suggest that the primary amine function group acts as a capping agent in the formation of $\mathrm{MgO}$ NPs.

The XRD techniques are widely used to determine the phase of MgO NPs. Figure 3B shows the XRD profile of St-MgO NPs synthesized using the $S$. trilobatum extract. The XRD strongest peak at $2 \theta$ value match with the crystal plane of $39.44^{\circ}=(111), 45.86^{\circ}=(200), 66.89^{\circ}=(220)$, $80.50^{\circ}=(311)$ and $84.89^{\circ}=(222)$ of MgO NPs. The $2 \theta$ value of NPs found to match with JCPDS-89-4248, confirming the formation of $\mathrm{MgO}$ NPs in crystalline nature. For Che-MgO NPs, $2 \theta$ value of $36.52^{\circ}=(111), 62.77^{\circ}=(220)$ and $80.60^{\circ}=(311)$, which is corresponding to the crystal plane of 111, 220 and 311 found to match with JCPDS45-0946 (figure 4B). Previously, Ganapathi et al [7] described the green synthesis of magnesium NP using orange fruit waste with $21 \mathrm{~nm}$ in size. Renata [24] explained the crystal nature of magnesium NPs synthesized from A. abrotanum was $10 \mathrm{~nm}$ in size and have antioxidant and photocatalytic activities.

\subsection{EDX, SEM and particle-size analyses}

The element composition of $\mathrm{MgO} \mathrm{NPs}$ is analysed using EDX to confirm the purity of NPs. St-MgO NPs have $53.76 \%$ of magnesium and $46.23 \%$ of oxygen

Table 1. Antioxidant activities of St-MgO and Che-MgO nanoparticles.

\begin{tabular}{lcc}
\hline Nanoparticles & Concentration $\left(\mu \mathrm{g} \mathrm{ml}^{-1}\right)$ & Mean $\pm \mathrm{SD}$ \\
\hline St-MgO & 50 & $22.50 \pm 0.28$ \\
& 100 & $63.83 \pm 0.72$ \\
& 200 & $81.16 \pm 0.60$ \\
& 500 & $84.50 \pm 0.28$ \\
& 1000 & $89.83 \pm 0.44$ \\
Che-MgO & 50 & $21.00 \pm 0.57$ \\
& 100 & $59.00 \pm 0.57$ \\
& 200 & $74.66 \pm 1.76$ \\
& 500 & $81.16 \pm 0.60$ \\
Control & 1000 & $85.50 \pm 1.04$ \\
& 50 & $19.50 \pm 0.28$ \\
& 100 & $27.16 \pm 0.72$ \\
& 200 & $42.33 \pm 0.88$ \\
& 500 & $65.16 \pm 0.44$ \\
& 1000 & $67.50 \pm 1.25$ \\
\hline
\end{tabular}

Results are expressed in mean $\pm \mathrm{SD}$. 
Table 2. ANOVA test between and within group of control, St-MgO and Che- $\mathrm{MgO}$ nanoparticles.

\begin{tabular}{llrrrr}
\hline Nanoparticles & & Sum of square & Mean square & \multirow{2}{*}{$F$} & Sig. \\
\hline \multirow{2}{*}{ St-MgO } & Between group & 8233.100 & 2058.275 & 656.896 & $0.000^{*}$ \\
& Within group & 31.333 & 3.133 & & \\
& Total & 8264.433 & & & \\
Che-MgO & Between group & 9027.733 & 2256.933 & \multirow{2}{*}{3.009} & $0.000^{*}$ \\
& Within group & 7.500 & 0.750 & & \\
& Total & 9035.233 & & & \\
& Between group & 5658.333 & 1414.583 & 744.518 & $0.000^{*}$ \\
& Within group & 19.000 & 1.900 & & \\
& Total & 5677.333 & & & \\
\hline
\end{tabular}

All the results are statistically significant $(P$ value $\leq 0.05)$.

Sig., significant, $* P \leq 0.05$.

Table 3. Antibacterial activity of St-MgO nanoparticles against bacterial pathogens.

\begin{tabular}{lccccc}
\hline & \multicolumn{3}{c}{ Different concentrations of St-MgO NPs $\left(\mathrm{mg} \mathrm{l}^{-1}\right)$} & $\begin{array}{c}\text { Control } \\
\text { Pathogens }\end{array}$ \\
\cline { 2 - 5 } & 25 & 50 & 75 & 100 & $\begin{array}{c}\text { Streptomycin, } \\
\left.10 \mu \mathrm{g} \mathrm{ml}^{-1}\right)\end{array}$ \\
\hline E. coli & $12.00 \pm 0.50$ & $12.00 \pm 1.00$ & $13.00 \pm 0.50$ & $16.66 \pm 1.00$ & $14.66 \pm 1.00$ \\
B. subtilis & $13.00 \pm 1.52$ & $13.33 \pm 0.59$ & $14.00 \pm 0.50$ & $16.00 \pm 1.44$ & $13.16 \pm 0.50$ \\
S. pyogenes & $15.16 \pm 0.18$ & $15.00 \pm 0.50$ & $15.66 \pm 0.45$ & $13.66 \pm 0.62$ & $13.82 \pm 0.50$ \\
\hline
\end{tabular}

The resulted zone of inhibition $(\mathrm{mm})$ is expressed in mean $\pm \mathrm{SD}$.

Table 4. Antibacterial activity of Che- $\mathrm{MgO}$ nanoparticles against bacterial pathogens.

\begin{tabular}{|c|c|c|c|c|c|}
\hline \multirow[b]{2}{*}{ Pathogens } & \multicolumn{4}{|c|}{ Different concentrations of Che-MgO NPs $\left(\mathrm{mg} \mathrm{l}^{-1}\right)$} & \multirow{2}{*}{$\begin{array}{c}\text { Control } \\
\text { (Streptomycin, } \\
10 \mu \mathrm{g} \mathrm{ml}^{-1} \text { ) }\end{array}$} \\
\hline & 25 & 50 & 75 & 100 & \\
\hline E. coli & $12.83 \pm 0.76$ & $13.00 \pm 1.52$ & $13.50 \pm 0.76$ & $15.16 \pm 0.63$ & $12.83 \pm 0.50$ \\
\hline B. subtilis & $12.50 \pm 0.76$ & $12.00 \pm 1.00$ & $14.00 \pm 1.04$ & $13.00 \pm 0.50$ & $14.83 \pm 0.50$ \\
\hline S. pyogenes & $13.16 \pm 0.83$ & $12.33 \pm 0.41$ & $10.50 \pm 0.50$ & $13.83 \pm 0.78$ & $12.62 \pm 1.00$ \\
\hline
\end{tabular}

The resulted zone of inhibition $(\mathrm{mm})$ is expressed in mean $\pm \mathrm{SD}$.

(figure 3C). Che-MgO NPs have $83.26 \%$ of magnesium and $16.74 \%$ of oxygen (figure $4 \mathrm{C}$ ). The EDX analysis refers to strong signal in the magnesium region of St-MgO and Che$\mathrm{MgO}$ that confirms the presence of $\mathrm{MgO}$ NPs.

SEM images of the St-MgO and Che-MgO NPs observed under various magnifications like $5000 \times, 10,000 \times, 20,000 \times$ and 30,000 $\times$ (figures 3D and 4D). These figure suggested that $\mathrm{St}-\mathrm{MgO}$ and Che-MgO NPs are aggregated and are spherical in shape. Particle-size analysis confirmed that the average size of St-MgO and Che-MgO NPs was 30 and $42 \mathrm{~nm}$, respectively (figures $3 \mathrm{E}$ and 4E). Krishnamoorthy et al [11] synthesized $\mathrm{MgO}$ NP exhibited spherical structure with $231 \mathrm{~nm}$ size and a small amount of aggregated particles.

\subsection{Antioxidant activity of $\mathrm{MgO} \mathrm{NPs}$}

The radical scavenging activity of $\mathrm{MgO}$ NPs was increased in dose-dependent manner. DPPH scavenging activity of St$\mathrm{MgO}$ NPs is significantly higher with $\mathrm{IC}_{50} 72.24 \mu \mathrm{g} \mathrm{ml}^{-1}$ when compared with control ascorbic acid $\left(\mathrm{IC}_{50} 33.46\right.$ $\mu \mathrm{g} \mathrm{ml}^{-1}$ ) and Che-MgO NPs $\left(\mathrm{IC}_{50} 66.74 \mu \mathrm{g} \mathrm{ml}^{-1}\right.$ ) (tables 1 and 2). The leaves of $S$. trilobatum were a rich source of several antioxidant components such as chlorogenic, caffeic, rosmarinic acid, total polyphenols and total flavonoids [15], the NPs synthesized from this source had excellent antioxidant activities. Selvam et al [25] demonstrated DPPH scavenging activity by using Aspergillus flavus-mediated NPs 
Table 5. ANOVA for the data on inhibition zone of St-MgO and Che-MgO nanoparticles against bacterial pathogens.

\begin{tabular}{|c|c|c|c|c|c|c|}
\hline Pathogens & Nanoparticles & & Sum of square & Mean square & $F$ & Sig. \\
\hline \multirow[t]{6}{*}{ E. coli } & \multirow[t]{3}{*}{ St-MgO } & Between group & 32.250 & 10.750 & \multirow[t]{3}{*}{17.200} & \multirow[t]{3}{*}{$0.001 *$} \\
\hline & & Within group & 5.00 & 0.625 & & \\
\hline & & Total & 37.250 & & & \\
\hline & \multirow[t]{3}{*}{ Che-MgO } & Between group & 15.945 & 5.315 & \multirow[t]{3}{*}{5.455} & \multirow[t]{3}{*}{$0.003^{*}$} \\
\hline & & Within group & 7.794 & 0.947 & & \\
\hline & & Total & 23.739 & & & \\
\hline \multirow[t]{6}{*}{ B. subtilis } & \multirow[t]{3}{*}{ St-MgO } & Between group & 15.092 & 5.031 & \multirow[t]{3}{*}{5.106} & \multirow[t]{3}{*}{$0.029 *$} \\
\hline & & Within group & 7.881 & 2.333 & & \\
\hline & & Total & 22.973 & & & \\
\hline & \multirow[t]{3}{*}{ Che-MgO } & Between group & 7.833 & 2.611 & \multirow[t]{3}{*}{3.581} & \multirow[t]{3}{*}{0.066} \\
\hline & & Within group & 5.833 & 3.708 & & \\
\hline & & Total & 13.667 & & & \\
\hline \multirow[t]{6}{*}{ S. pyogenes } & \multirow[t]{3}{*}{ St-MgO } & Between group & 7.642 & 2.547 & \multirow[t]{3}{*}{11.489} & \multirow[t]{3}{*}{$0.003 *$} \\
\hline & & Within group & 1.774 & 2.316 & & \\
\hline & & Total & 9.416 & & & \\
\hline & \multirow[t]{3}{*}{ Che-MgO } & Between group & 29.459 & 9.820 & \multirow[t]{3}{*}{4.427} & \multirow[t]{3}{*}{$0.041 *$} \\
\hline & & Within group & 17.746 & 2.218 & & \\
\hline & & Total & 47.205 & & & \\
\hline \multirow[t]{3}{*}{ Control } & & Between group & 22.220 & 4.444 & \multirow[t]{3}{*}{2.774} & \multirow[t]{3}{*}{$0.039 *$} \\
\hline & & Within group & 19.223 & 4.913 & & \\
\hline & & Total & 41.444 & & & \\
\hline
\end{tabular}

All the results are statistically significant except Che-MgO NPs against Bacillus ( $P$ value $\leq 0.05)$.

Sig., significant, $* P<0.05$.

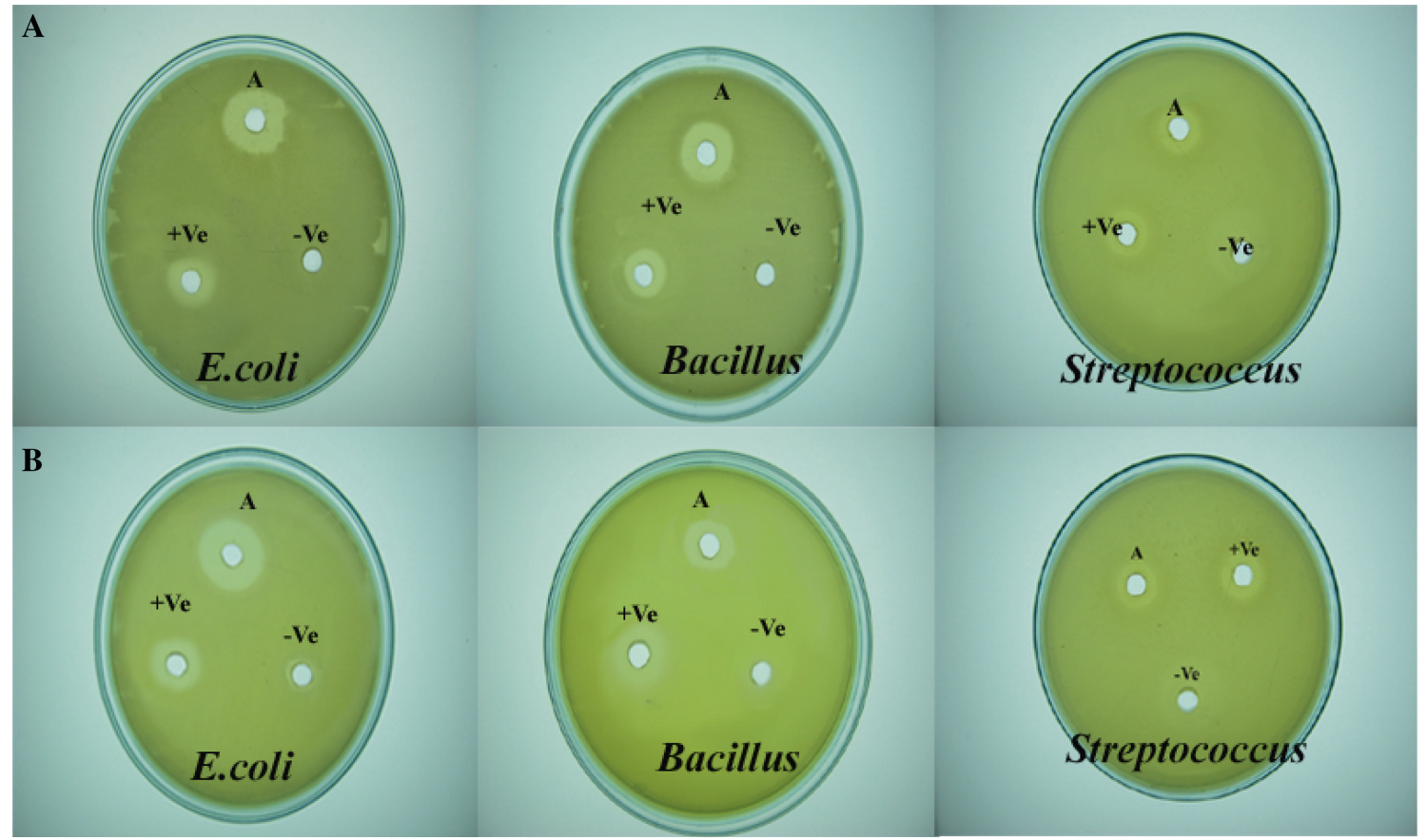

Figure 5. Antibacterial activity of (A) St-MgO and (B) Che-MgO nanoparticles against E. coli, B. subtilis and S. pyogenes. A, $100 \mathrm{mg} \mathrm{ml}^{-1}$ concentration of $\mathrm{MgO} \mathrm{NPs},+\mathrm{Ve}, 10 \mu \mathrm{g} \mathrm{ml}^{-1}$ concentration of streptomycin (positive control), -Ve, Millipore water (negative control). 
showing $80 \%$ activity at $400 \mu \mathrm{g} \mathrm{ml}^{-1}$. In another study, silver NPs synthesized from the leaf extract of Excoecaria agallocha showed 90\% DPPH scavenging activity at $1 \mathrm{mg} \mathrm{ml}^{-1}$ concentration [2].

\subsection{Antibacterial activity of $\mathrm{MgONPS}$}

S. trilobatum and sodium hydroxide-mediated MgO NPs show an excellent antibacterial activity against bacterial pathogens. The highest zone of inhibition was observed in St-MgO against $E$. coli with a diameter of $16.66 \pm 0.66 \mathrm{~mm}$ at a concentration of $100 \mathrm{mg} \mathrm{ml}^{-1}$ and the lowest inhibition was observed in S. pyogenes with a zone diameter of $13.66 \pm$ $2.08 \mathrm{~mm}$ at the same concentration (table 3). S. trilobatummediated $\mathrm{MgO}$ NPs showed effective antibacterial activity in E. coli. Likewise, Che-MgO NPs show maximum zone of inhibition observed in E. coli $(15.16 \pm 0.44 \mathrm{~mm})$ and a minimum zone of inhibition in $S$. pyogenes $(13.83 \pm 0.92 \mathrm{~mm})$ at a concentration of $100 \mathrm{mg} \mathrm{ml}^{-1}$ (tables 4 and 5). Figure 5 shows the antibacterial activity of St-MgO and Che-MgO NPs against bacterial pathogens at a concentration of $100 \mathrm{mg} \mathrm{ml}^{-1}$. Doss et al [6] explained that the antibacterial activity of $\mathrm{MgO}$ NPs against $E$. coli was due to a broad range of oxygen present on the surface of magnesium. Krishnamoorthy et al [11] described the effect of magnesium NPs against Gram-positive and Gram-negative bacteria with the minimum inhibitory concentration of $500 \mu \mathrm{g} \mathrm{ml}^{-1}$ against Pseudomonas and E. coli. Doss et al [6] and Krishnamoorthy et al [11] explained the enhanced antibacterial activity of magnesium NPs due to ROS and lipid peroxide with a defect of oxygen present on the morphology of particles. MgO NPs, strong in electrostatic interaction with bacterial surface led to cell death $[28,29]$.

\section{Conclusion}

The present study reported that $\mathrm{MgO}$ NPs synthesized by precipitation method using sodium hydroxide and $S$. trilobatum leaf extract act as a capping and reducing agent with magnesium nitrate precursor. Synthesized $S$. trilobatum-mediated $\mathrm{MgO}$ NPs are spherical in shape and is $30 \pm 6 \mathrm{~nm}$ in size. $\mathrm{MgO}$ NPs capped with $S$. trilobatum have excellent antioxidant properties. Also, it shows promising antibacterial activity against $E$. coli and B. subtilis at a concentration of 100 $\mu \mathrm{g} \mathrm{ml}^{-1}$. Thus, we conclude $S$. trilobatum-mediated $\mathrm{MgO}$ NPs can be used to treat the diseases caused by free radicals.

\section{Acknowledgements}

We acknowledge the management of Sri Krishna Arts and Science College, Coimbatore, Tamil Nadu, India, for providing necessary facilities to carry out this study.

\section{References}

[1] Alaa Y G, Tawfiq M A, Akl M M and Muhand W A 2017 ARPN J. Agric. Biol. Sci. 10293

[2] Al-Gaashani R, Radiman S, Al-Douri Y, Tabet N and Daud A R 2012 J. Alloys Compd. 5271

[3] Al-Hazmi F, Alnowaiser F, Al-Ghamdi A A, Aly M M, Al-Tuwirqi R M and El-Tantawy F 2012 Superlattices Microstruct. 52200

[4] Alvarado E, Torres-Martinez L M and Fuentes A F 2000 Polyhedron 192345

[5] Bhatte K D, Sawant D N, Watile R A and Bhanage B M 2012 Mater. Lett. 6966

[6] Doss A, Muhamed M H and Dhanabalan R 2009 Indian J. Sci. Tech. 241

[7] Ganapathi R K, Ashok C H, Venkateswara R K, Shilpa Chakra C H and Akshaykranth A 2015 Int. J. Adv. Res. Phys. Sci. 21

[8] Huang L, Li D Q, Lin Y J, Evans D G and Duan X 2005 Chin. Sci. Bull. 50514

[9] Jawhar M, Amalan R G and Jeyaseelan M 2004 Plant Tissue Cult. Biotechnol. 14107

[10] Kanchana D, Jayanthi M, Kanchana D, Saranraj P and Sujitha D 2013 Int. J. Microbiol. Res. 4300

[11] Krishnamoorthy K, Manivannan G, Kim S J, Jeyasubramanian K and Premanathan M 2012 J. Nanoparticle Res. 141063

[12] Kumar D, Reddy Yadav L S, Lingaraju K, Manjunath K, Suresh D, Prasad D et al 2015 AIP Conf. Proc. 1665050145

[13] Li Y J, Li D Q, Wang G, Huang L and Duan X 2005 J. Mater. Sci. Mater. Med. 1653

[14] Vanaja M, Paulkumar K, Baburaja M, Rajeshkumar S, Gnanajobitha G, Malarkodi C et al 2014 Bioinorg. Chem. Appl. 2014 8

[15] Marina Z, Mariana P, Thiele F B, Aline A B, Robson B F, Michel M M et al 2012 Molecules 1712560

[16] Narendhran S, Rajiv P, Vanathi P and Rajeshwari S 2014 Int. J. Pharm. Pharm. Sci. 6319

[17] Narendhran S, Rajiv P and Rajeshwari S 2016 Bull. Mater. Sci. 391

[18] Pacholski C, Kornowski A and Weller H 2002 Angew. Chem. Int. Ed. 411188

[19] Palanisamy G and Pazhanivel T 2017 Int. Res. J. Eng. Tech. 4137

[20] Raghupati R K, Koodali R T and Manna A C 2011 Langmuir 274020

[21] Rai M and Ingle A 2012 Appl. Microbiol. Biotechnol. 94287

[22] Rajeshwari S, Rahman P K S M, Rajiv P, Narendhran S and Venckatesh R 2014 Spectrochim. Acta Part A 129255

[23] Rajiv P, Rajeshwari S and Venckatesh R 2013 Spectrochim. Acta Part A 112384

[24] Renata D 2016 Iran. J. Sci. Technol. A 19

[25] Selvam N C S, Kumar R T, Kennedy L J and Vijaya J J 2011 J. Alloys Compd. $\mathbf{5 0 9} 9809$

[26] Shahjahan M, Sabitha K E, Jamu M and Shyamala Devi C S 2004 Indian J. Med. Res. 120194

[27] Sri Vishnupriya R, Narendhran S and Rajeshwari S 2016 Bull. Mater. Sci. 39361

[28] Stoimenov P K, Klinger R L, Marchin G L and Klabunde K J 2002 Langmuir 186679

[29] Sundrarajan M, Suresh J and Gandhi R R 2012 Dig. J. Nanomater. Biostruct. 7983 